\title{
Avaliação da vulnerabilidade das praias oceânicas do Rio de Janeiro à inundação e à erosão costeira durante eventos de tempestade
}

Pedro Torres Costa, Pedro Antonio da Silva Piacesi, Flavia Moraes Lins de Barros, UFRJ.

Copyright 2021, SBGf - Sociedade Brasileira de Geofísica.

This paper was prepared for presentation during the $17^{\text {th }}$ International Congress of the Brazilian Geophysical Society held in Rio de Janeiro, Brazil, 8-11 November 2021.

Contents of this paper were reviewed by the Technical Committee of the $17^{\text {th }}$ International Congress of the Brazilian Geophysical Society and do not necessarily represent any position of the SBGf, its officers or members. Electronic reproduction or storage of any part of this paper for commercial purposes without the written consent of the Brazilian Geophysical Society is prohibited.

\begin{abstract}
Praias arenosas são suscetíveis à erosão e inundação costeiras por efeito de ondas de tempestade, o que pode ser agravado em um cenário de mudanças climáticas e aumento do nível do mar. No litoral da cidade do Rio de Janeiro são recorrentes ressacas que causam danos ao patrimônio público e privado e colocam em risco físico e econômico diversos setores da sociedade. Torna-se fundamental, portanto, compreender a dinâmica erosiva costeira, avaliando as características da zona costeira e as condições oceanográficas que podem agravar a situação. $O$ objetivo deste trabalho é contribuir com a avaliação da vulnerabilidade costeira da orla oceânica da cidade do Rio de Janeiro a partir da elaboração de um índice de vulnerabilidade, que leve em consideração diversos aspectos levantados em mapeamentos anteriores. Além disso, buscou-se a integração com outras metodologias, além de observações históricas da recorrência de tempestades na cidade e seus efeitos sobre a orla. Desta forma, o índice de vulnerabilidade física foi adaptado a partir de Gornitz (1991) e da proposta aplicada por Lins de Barros (2010; 2011) na Região dos Lagos (RJ) para ser aplicado à abordagem de mapeamento costeiro Smartline (Sharples, 2006), o que possibilitou integrar variáveis geológicas, geomorfológicas, topográficas e oceanográficas em um único índice. Esta metodologia se estrutura em
\end{abstract}

três passos. O primeiro passo consiste em avaliar as condições mais gerais, como o material da praia, a sua orientação em relação à entrada de ondas de tempestade e o relevo local, identificando trechos potencialmente vulneráveis. $O$ segundo passo estabelece uma classificação regional identificando áreas vulneráveis, incluindo as feições do póspraia, a granulometria dos sedimentos e a morfodinâmica praial. E o terceiro passo tem a intenção de produzir uma análise mais detalhada, incluindo características de escala local, como a altura do pós-praia, a declividade da zona de surfe e a altura das ondas de tempestade, o que demandou a realização de simulações das condições de ondas. Para isto foi utilizado o software SiSBaHiA, desenvolvido pela CoppeUFRJ. A síntese destes três passos resultou em um índice que, integrando estas variáveis, permite uma avaliação em diferentes escalas espaciais. Ademais, a análise local do arco praial LeblonIpanema-Arpoador a partir da metodologia desenvolvida por Sallenger (2000), que avalia a altura da duna frontal, as características das ondas e a declividade da face de praia, nos permitiu mapear de forma geral os trechos que estão sujeitos à colisão e transposição de ondas por efeito de ressacas, o que pode ser agravado em episódios de maré alta e maré meteorológica (storm surge). Assim, este trabalho teve como resultado o mapeamento das áreas mais vulneráveis à erosão costeira, assim como às inundações, a partir de índice desenvolvido, em avaliação comparativa com outros índices. Os próximos passos preveem a inclusão de dados socioeconômicos que permitam avaliar as características da população residente e que trabalha nas praias cariocas e os impactos sofridos em decorrência de ressacas do mar. 